A Social Judgment? Extralegal Contrast Effects in Hypothetical Legal Decision Making Max E. Butterfield ${ }^{1}$

Alexandra N. Bitter ${ }^{2}$

Author note: Study 1 was presented as a poster at the 2017 Annual Meeting of the Society for Personality and Social Psychology in San Antonio, TX. Studies 1 and 2 were presented as a poster at the 2017 Annual Meeting of the Western Psychological Association in Sacramento, CA. A pre-print of the manuscript is hosted at PsyArxiv, and the full study materials; data; and code can be accessed at https://osf.io/edty2/?view_only=c0c42f0ac2bf4e53a74cb230a4b83421.

${ }^{1}$ Corresponding author; email: mbutter@pointloma.edu; Point Loma Nazarene University, San Diego, CA

${ }^{2}$ The University of Wyoming, Laramie, WY 


\begin{abstract}
Social judgments in ambiguous situations often rely on heuristics and biases, and legal decision makers are often faced with evidence that does not clearly favor one decision over another. Across two studies, we tested whether one extralegal factor, contrast cases, influenced decision making when judicial factors were held constant. In Study 1, participants $(n=100)$ evaluated whether an imagined prosecutor had sufficient evidence to send the same three target cases to trial. Before deciding these cases, though, the participants first evaluated cases with either relatively stronger or weaker evidence than the targets. Those in the weak-case comparison group were significantly more likely to send target cases to trial, and they believed the prosecutor had a stronger case. In Study 2, all participants $(n=100)$ evaluated hypothetical parole applications, but the method was otherwise the same as that used in Study 1. The same contrastoriented pattern emerged. Participants who first viewed weaker parole applications rated the identical targets as significantly more rehabilitated. Taken together, the results of these two studies suggest that contrast effects may be one extralegal factor involved in shaping individuallevel social judgments made in legal contexts such as grand juries and parole boards.
\end{abstract}

Key Words: Contrast Effects; Decision Making; Grand Juries; Parole Boards; Heuristics 
A Social Judgment? Extralegal Contrast Effects in Hypothetical Legal Decision Making Objectivity is a cornerstone of the American justice system, and legal decisions are supposed to be based on the strength of available evidence. Research findings do provide at least partial support for the ideal (Caplan, 2007): In many instances, strong cases win and weak cases do not (Devine, Clayton, Dunford, Seying, \& Pryce, 2001). However, what happens when the strength of evidence does not completely favor one side or the other? A growing body of research has demonstrated that a variety of extralegal factors affect legal decision making. Generally, ambiguous conditions in any domain increase the likelihood that heuristics and biases will influence social judgments (Kahneman, 2011), but we were especially curious about how they might affect legal decision making, especially when such processing might be inadvertently or systematically activated in all decision makers involved in a particular case (see e.g., London and Nunez, 2001 for an existing example). Among some of the most noteworthy of these are pretrial publicity; the CSI effect; and the race, sex, and gender of the defendant (Bjerregaard, Smith, Cochran \& Fogel, 2017; Devine, Buddenbaum, Houp, Studebaker, \& Stolle, 2009; Hester \& Hartman, 2017; Spohn, Gruhl, \& Welch, 1987).

Cases with middling evidentiary strength seem to be especially prone to the effects of extralegal factors like these (Bornstein \& Greene, 2011), perhaps because downstream legal decisions are made as the result of upstream group-level interactions between diverse groups of individuals. Therefore, in order to help understand these group processes further, we believe an underserved area of investigation lays yet farther upstream where initial individual-level social judgments first begin to influence decisions. Undoubtedly, both are important areas of investigation, but our express purpose in the present investigation was to focus on the role of ambiguity in basic social judgments made by individuals. Specifically, we wondered whether 
contrast cases presented before target cases might be an influence over and above the other extralegal factors that have been more thoroughly documented elsewhere. We hypothesized that making additional cases cognitively accessible to individual evaluators would subtly provide reference points for judging case strength, thereby influencing what otherwise appear to be objective ratings of target cases.

\section{Heuristics in Judgment and Decision Making}

The human decision making system is not perfect. It is built for speed, efficiency, and economy. Its processes have received considerable interest over the last three decades, and the repercussions of social judgment permeate society in areas as varied as politics, interpersonal relationships, medicine, the workplace, education, and the criminal justice system (e.g., Johnson et al., 2017; McNamara, Pitt-Catsouphes, Sarkisian, Besen, \& Kidahashi, 2016; Ruva, \& Guenther, 2017). One popular example from among the many heuristics and biases that have been discovered is the effect of physical attractiveness on character judgments. Especially beautiful people are more likely to be judged as well-endowed in unrelated matters, such as intelligence, interpersonal warmth, and competence (Dion, Berscheid, \& Walster, 1972; Eagly, Ashmore, Makhijani, \& Longo, 1991; Lorenzo, Biesanz, \& Human, 2010). Perhaps this is why, in mock jury studies, attractive defendants tend to receive lighter sentences and are less likely to be convicted than their less attractive counterparts are (Gunnell \& Ceci, 2010; Patry, 2008).

Social judgments based on prejudices and stereotypes like these typically rely on systematic processes: Rather than carefully deliberating decisions based on known facts about the individuals being evaluated, mental shortcuts bias and shape inferences instead (Nisbett \& Ross, 1980). Prospect Theory (Kahneman \& Tversky, 1979) is often used to help explain these processes. Originally proposed to explain decision making under conditions of risk, it has 
subsequently been applied to demonstrate that judgments and decisions across domains are not made in a rational vacuum. Instead, they are situated in the context of individual decision makers. Finding \$100 might be a windfall for someone who just lost a job, but it might be only a small consolation for someone else who just lost a month's pay in a poker game. The threshold for what each decision maker considers to be a windfall or a consolation appears to largely be determined by the expectational anchors in play in each situation. Crossover into the legal system has been demonstrated in civil suits. Plaintiffs who set a high anchor for their expected award value are typically awarded more money than those who ask for less, even when the facts of the case are held constant (Cialdini, 2009).

This Anchoring Effect (Tversky, \& Kahneman, 1974) is but one example of Social Judgment Theory's (Sherif \& Hovland, 1961) emphasis on the importance of reference points in decision making. For many years, in fact, researchers worked to resolve an apparent paradox in which some reference points were observed to create assimilation effects, whereas others lead to contrast effects (Biernat, M., 2012). Assimilation occurs when target stimuli are evaluated as more similar to an anchor/reference, whereas contrast creates the opposite effect, and evidence has mounted to demonstrating that assimilation and contrast are driven by the features of the references and stimuli that are cognitively accessible at the point of evaluation (Bless \& Schwarz, 2010). One example of this in a legal context, for instance, is that homicide is deemed much more severe a crime when compared to assault (contrast) rather than another homicide (assimilation), whereas assault is viewed less seriously when compared to homicide (contrast) than another assault (assimilation; Pepitone \& DiNubile, 1979).

Contrast effects. Writing about perception, the philosopher John Locke (1690) first described contrast effects by arguing that the same tepid bath water could feel different to the 
same person if they plunged one hand into a tub of ice cold water and the other into a tub of hot before submerging them both in the bath. To the hand that was previously in the cold water, the bath would feel hot, but to the hand that had been in the hot water, the bath water would feel frigid. Wundt (1907) introduced this idea as the Law of Psychical Contrast, one of the very first principles investigated by psychologists. He suggested that the intensity of physiological perceptions, such as the intensity of light or the weight of an object are calibrated with respect to other sensations that have been recently encountered.

These theories have been explored in modern day, with particular attention devoted to exploring the role of contrast in perception, and to detailing the ways in which contrast helps guide social judgments about other people. Illustrating the former case, for instance, music is judged to be good or bad in light of the quality of the music played directly prior to hearing it (Parker, Bascom, Rabinovitz, \& Zellner, 2008). With respect to the latter, it has been well established that people are judged to fit into social categories, at least in part, by how they compare and contrast to the exemplars used to represent those categories (Galesic, Goode, Wallsten, \& Norman, 2018; Moskowitz \& Roman, 1992; Newman \& Uleman, 1990; Tversky, 1977). Moreover, studies over the years have demonstrated the role of contrast extends beyond physiological and person-perception judgments and appears to apply to cognitions across the spectrum of judgment and decision making (Moskowitz, 2005, Plous, 1993; Kenrick \& Gutierres, 1980; Sherif \& Hovland, 1961). However, few studies have specifically explored in depth the ways in which contrast might affect decision making in legal contexts, and although the application is intuitive, empirical investigation has been limited (see e.g., Jones, Palmer, \& Bandy, 2015; Pepitone \& DiNubile, 1979). 
Heuristics and biases in legal decision making. Because the United States' justice system relies heavily on untrained volunteers for jury service, we believe it is particularly important to determine how social judgment affects legal decision making. Unfortunately, evidence does support the notion of consistent bias in some circumstances, especially in cases where the strength of evidence does not clearly favor one side or another. It is in these cases that jurors may find themselves unable to make decisions based solely facts of the cases they are considering, and they instead rely on intuitions, biases, or mental shortcuts to tip the scales in one direction or another (Kalven, Zeisel, Callahan, \& Ennis, 1966). Recently, there has been increased interest specifically in the role of extralegal social and cognitive factors in legal decision making. Many studies have been undertaken, for instance, to investigate how widespread societal problems like stereotypes and prejudice might affect different aspects of the judicial system, but others have focused on more specific phenomena like the effect of pretrial publicity or the effect of exposure to legal drama on television (Kramer, Kerr, \& Carroll, 1990; Ley, Jankowski, \& Brewer, 2012; Steblay, Besirevic, Fulero, \& Jimenez-Lorente, 1999). Other research has shown that even trained professionals may fall back on similar extralegal factors when under stress, preoccupied, or mentally overloaded (Leibovitch, 2016a; Leibovitch, 2016b; Nugent, 1994). Taken together, these lines of research demonstrate that heuristic processing is common and could likely be explored in either laypersons or professionals. However, the present study was designed to simply establish whether the basic effect exists. More specifically, it was designed to explore how contrast effects might affect decision making by those most likely to fall prey to it, non-professionals in a hypothetical context.

\section{The Present Studies}


Given the wide-reaching effect of contrast in domains ranging from physiological perception to social judgment, we were curious whether the same legal cases would be evaluated differently depending on the severity of recent cases with which they were embedded. Similar to Locke's (1690) tepid bath example, we specifically wondered whether weak-contrast comparison cases would make target cases appear strong, whereas strong-contrast target cases would make those same target cases appear weak, simply because of the directionally-oriented high evaluative contrast created by the cognitive accessibility of the recent comparators. Study 1 was designed to test this hypothesis using a hypothetical grand jury experience. A grand jury setting was chosen for the initial study because, unlike petit juries, they do not reach final case outcome decisions and they can make decisions about multiple cases. Instead, individuals who sit on grand juries decide if the cases they consider have sufficient evidence for a prosecutor to send them to trial, and the jurors are typically exposed to multiple cases in sequence over the course of their time spent serving. Thus, it seemed more ecologically valid to ask participants to consider multiple cases. Similarly, parole boards were chosen as the setting for Study 2 for the same reason: Parole boards in many jurisdictions typically evaluate multiple cases in a sequence, often even multiple in the same sitting. The general hypothesis for both studies was that evaluations of case strength would be higher for participants whose expectations were anchored by weakcontrast comparison cases than for those who were anchored by strong-contrast comparison cases.

\section{Study 1}

Method. We conducted an a priori analysis with $\mathrm{G}^{*}$ Power software to estimate sufficient powering for the initial study (assumptions: $\alpha=.05,1-\beta=.80, f=.25$ ), and a sample size of approximately 100 was indicated in order to detect the planned between-groups comparisons in 
our mixed-model design. The participants were mTurk workers $(n=100)$ over the age of $18(M$ $=37.58, S D=13.38)$ and located in the United States. There were 51 men and 49 women. All but $5 \%$ reported at least "some college." We did not specifically recruit participants with jury experience, but twenty reported prior petit jury service, and one reported prior grand jury service. We used a 2 (between: strong contrast vs. weak contrast) X 2 (within: contrast case evaluation vs. target case evaluation) mixed model design. All participants evaluated both three contrast cases and three target cases. Half were assigned to the weak-contrast condition, and the other half were assigned to the strong-contrast condition. All participants were asked to imagine sitting on a grand jury, and using the directions below, ${ }^{3}$ they were told their goal was to determine whether a prosecutor had sufficient evidence to send six cases to trial.

Imagine you've been selected to be a member of a grand jury for Los Angeles County. You're going to look at some simplified information from several simulated cases. It's important to note that the names have been changed for reasons of privacy. Your job is to help determine if there's enough evidence to go to trial. The standard you should use is not reasonable doubt. Instead, it's to determine if the defendant could have committed the crime. Remember, your job is to help determine if there's enough evidence to go to trial. The defendant is the person accused of the crime. The prosecutor is the attorney who is trying to convince you. The names have been changed for reasons of privacy.

Each of these "case files" was simply a page listing case-relevant characterological and "known facts" about a male defendant with a common name (e.g., James Hall) who was accused of a violent crime (e.g., assault with a deadly weapon). Appendix A contains a representative example of a target case, and the full study materials; data; and code for both Study 1 and 2 can be accessed at https://osf.io/edty2/?view_only=c0c42f0ac2bf4e53a74cb230a4b83421. The contrast cases were very similar, only they contained either more evidence (strong contrast condition) or less evidence (weak contrast condition) than the target cases. The cases were

\footnotetext{
${ }^{3}$ The original instructions for Study 1 included a typo in the first line of the directions. The word "selected" was inadvertently omitted from the first sentence. Fortunately, a multiple choice item was included directly after the directions to verify they had understood the directions, and all participants reported the correct answer.
} 
presented one at a time, and while considering each one, the participants rated their agreement with four statements $(1=$ strongly disagree; 5 = strongly agree $)$ : The defendant seems dangerous, the defendant is likely guilty, there is enough evidence to go to trial, and the prosecutor would have a good case. ${ }^{4}$ In the strong contrast condition, the target cases were randomly embedded amongst an additional three cases with five pieces of evidence each. In the weak contrast condition, they were embedded amongst an additional three cases with only one piece of evidence each. Regardless of experimental condition, all participants evaluated the same three target cases. These presented three pieces of evidence against each defendant, and they were identical in every way.

\section{Table 1}

Study 1 Mixed-Model ANOVA Inferential Statistics

\begin{tabular}{|c|c|c|c|c|c|}
\hline & & DF & $\mathbf{F}$ & p & $\begin{array}{c}\eta_{\text {partial }}^{2} \\
{[90 \% \mathrm{Cl}]}\end{array}$ \\
\hline \multirow[t]{3}{*}{ DANGEROUS } & Case Type & $1(98)$ & 38.82 & $<.001$ & $.28[.16, .39]$ \\
\hline & Contrast Type & $1(98)$ & 61.24 & $<.001$ & $.39[.26, .48]$ \\
\hline & Case Type * Contrast Type & $1(98)$ & 179.62 & $<.001$ & $.65[.55, .71]$ \\
\hline \multirow[t]{3}{*}{ GUILTY } & Case Type & $1(98)$ & .73 & .395 & $.01[0, .06]$ \\
\hline & Contrast Type & $1(98)$ & 20.77 & $<.001$ & $.18[.07, .28]$ \\
\hline & Case Type * Contrast Type & $1(98)$ & 129.84 & $<.001$ & $.57[.46, .65]$ \\
\hline \multirow[t]{3}{*}{ SEND TO TRIAL } & Case Type & $1(98)$ & 2.00 & .160 & $.02[0, .09]$ \\
\hline & Contrast Type & $1(98)$ & 12.75 & .001 & $.12[.03, .22]$ \\
\hline & Case Type * Contrast Type & $1(98)$ & 52.70 & $<.001$ & $.57[.23, .45]$ \\
\hline \multirow[t]{3}{*}{ GOOD CASE } & Case Type & $1(98)$ & 1.55 & .216 & $.02[0, .08]$ \\
\hline & Contrast Type & $1(98)$ & 8.46 & .005 & $.08[.02, .17]$ \\
\hline & Case Type ${ }^{*}$ Contrast Type & $1(98)$ & 122.07 & $<.001$ & $.56[.44, .63]$ \\
\hline
\end{tabular}

\footnotetext{
${ }^{4}$ It is important to note that these items were not intended to be a proxy measure of the actual outcome decision that would ultimately be made by a grand jury. They were designed to assess individual-level social judgments made by participants acting as individuals. Grand juries are complex groups influenced not just by a single individual's cognitive processes, but instead by the interaction between those processes, the social environment, and a variety of other factors unique to each person; group of people; and situation.
} 
Results. The ratings given to all the target cases on each of the four dependent variables were averaged across targets to create overall scores for each dependent variable. The results were analyzed with a 2 (Case Type: contrast vs. target) X 2 (Contrast Type: strong vs. weak) mixed model ANOVA. Case Type was a within-subjects variable, and Contrast Type was between. A planned comparison manipulation check was conducted to determine whether weak contrast cases were indeed judged to be weaker than strong contrast cases, and the remaining planned comparisons assessed the effect of strong vs. weak contrast cases on subsequent target case evaluations. See Table 1 for ANOVA statistics and Table 2 for the descriptive statistics and planned comparisons.

\section{Table 2}

\section{Study 1 Planned Comparison Descriptive Statistics}

Note: Target comparisons were the primary outcome measure, whereas contrast comparisons were the manipulation check.

\begin{tabular}{|c|c|c|c|c|c|c|c|}
\hline & & & $\mathbf{n}$ & M & SD & $\begin{array}{c}\text { Mean Difference } \\
{[95 \% \mathrm{Cl}]}\end{array}$ & $\begin{array}{c}\text { Cohen's D } \\
{[95 \% \mathrm{CI}]}\end{array}$ \\
\hline \multirow[t]{4}{*}{ DANGEROUS } & Target & Weak & 50 & 3.65 & .80 & .01 & .02 \\
\hline & & Strong & 50 & 3.64 & .71 & {$[-.29, .31]$} & {$[-.37, .41]$} \\
\hline & Contrast & Weak & 50 & 2.19 & .87 & 1.98 & 2.82 \\
\hline & & Strong & 50 & 4.17 & .48 & {$[1.70,2.26]$} & {$[2.26,3.37]$} \\
\hline \multirow[t]{4}{*}{ GUILTY } & Target & Weak & 50 & 3.01 & .67 & .21 & .32 \\
\hline & & Strong & 50 & 2.79 & .67 & {$[-.05, .48]$} & {$[-.08, .71]$} \\
\hline & Contrast & Weak & 50 & 2.15 & .81 & 1.39 & 1.74 \\
\hline & & Strong & 50 & 3.53 & .78 & {$[1.07,1.70]$} & {$[1.28,2.20]$} \\
\hline \multirow[t]{4}{*}{ SEND TO TRIAL } & Target & Weak & 50 & 2.93 & 1.00 & .49 & .52 \\
\hline & & Strong & 50 & 2.45 & .85 & {$[.12, .86]$} & {$[.12, .92]$} \\
\hline & Contrast & Weak & 50 & 2.03 & .77 & 1.57 & 1.90 \\
\hline & & Strong & 50 & 3.60 & .88 & {$[1.24,1.89]$} & {$[1.43,2.37]$} \\
\hline \multirow[t]{4}{*}{ GOOD CASE } & Target & Weak & 50 & 2.75 & .96 & .45 & .50 \\
\hline & & Strong & 50 & 2.29 & .86 & {$[.09, .81]$} & {$[.10, .90]$} \\
\hline & Contrast & Weak & 50 & 1.93 & .78 & 1.38 & 1.56 \\
\hline & & Strong & 50 & 3.31 & .98 & {$[1.03,1.73]$} & {$[1.10,2.00]$} \\
\hline
\end{tabular}


The results of the manipulation check revealed a significant effect of contrast type on evaluation of the contrast cases themselves. Participants in the weak group evaluated the contrast cases significantly more negatively than did those in the strong group for all four dependent variables, which indicates the manipulation worked as intended: Weak contrast cases were seen as weak, and strong contrast cases were seen as strong. In addition, the results of the planned comparison of the effect of contrast type on the target cases revealed that they were evaluated as significantly weaker by those who saw strong contrasts than by those who saw weak contrasts, despite the fact that the targets were precisely the same cases. More specifically, they were evaluated as less likely to be sent to trial and were seen as worse cases. Moreover, we also observed a significant crossing interaction between Case Type and Contrast Type, which supports the notion of contrast induced evaluative changes away from the evaluative anchors provided by the contrast cases. In other words, the contrast cases appeared to repel the evaluations of the target cases away from the anchors provided by the contrast cases. Taken together, the results of Study 1 were in line with predictions logically extending from Social Judgment Theory, and they demonstrate that participants evaluated the strength of evidence in the identical target cases by contrasting them with either the strong or weak cases with which they were embedded.

\section{Study 2}

Study 2 was a conceptual replication of Study 1. Rather than a grand jury setting, it explored whether the observed contrast effects would affect evaluations of inmate rehabilitation in a hypothetical parole board setting. Parole boards' procedures, as well as their member composition; background; training; and experience can vary considerably by jurisdiction. However, we believed they were an ideal subject of study for a conceptual follow-up study 
because sequential evaluation of cases is a common feature of parole boards, just as it is of grand juries. As in Study 1, it is important to note that the dependent measures of Study 2 were not intended to be a proxy measure of the actual outcome decision that would ultimately be made by a parole board. Parole boards are complex groups influenced not just by a single individual's cognitive processes, but instead by the interaction between those processes, the social environment, and a variety of other factors unique to each person, group of people, and situation. With that in mind, we set out to explore the individual-level social judgments made by participants acting as individual legal decision makers.

Method. We used the same 2 X 2 mixed method as Study 1, but we asked the participants to imagine themselves on a parole board instead of a grand jury. We again conducted an a priori analysis with $\mathrm{G}^{*}$ Power software to estimate sufficient powering for the initial study (assumptions: $\alpha=.05,1-\beta=.80, \mathrm{f}=.25$ ), and a sample size of approximately 100 was again indicated in order to detect the planned between-groups comparisons in our mixed-model design. The materials, etc. are again all available in the link referenced in Study 1. The participants were again mTurk workers $(n=100)$ over the age of $18(M=36.31, S D=11.71)$ located in the United States. There were 38 men, 61 women, and 1 undisclosed. All but 13 reported at least "some college." We again did not recruit participants with parole board experience, but somewhat surprisingly, seven reported previous experience sitting on one. Regardless of experience, all participants were asked imagine sitting on a parole board, and they were given the following instructions.

Imagine you've been selected to be a member of a parole board for Los Angeles County. You're going to look at some simplified information from several simulated cases. It's important to note that the names have been changed for reasons of privacy. Your job is to help determine if the offender should be released into the community under supervision and conditions of parole before granting the offender complete freedom. Remember, your job is to help determine if the prisoner should be released into the community under 
supervision and conditions of parole before granting complete freedom. Parole is the release of a prisoner temporarily or permanently before the completion of a sentence on the promise of good behavior. All prisoners you will review have served at least $75 \%$ of their sentences and are currently eligible for parole.

Participants again evaluated six cases, and each "case file" was simply a page of information with the available information against a male prisoner with same common names used in Study 1 (e.g., James Hall) and a violent crime for which they had been sentenced (e.g., assault with a deadly weapon). See Appendix B for a representative target case file. All the case files were presented one at a time. While considering each case, the participants were asked to rate their agreement with four statements $(1=$ strongly disagree; $5=$ strongly agree $)$ : The prisoner does not seem reformed, the prisoner would be a threat to society, the prisoner does not seem repentant, and the board should not grant parole. In the strong contrast condition, the target cases were randomly distributed amongst an additional three cases with five pieces of negative information about the prisoner in each case. In the weak contrast condition, they were distributed amongst an additional three cases with only one piece of negative information about the prisoner in each case. Regardless of experimental condition, all participants evaluated the same three target cases. These presented three pieces of information about each prisoner, and they were identical in every way.

Results. The ratings given to all the target cases on each of the four dependent variables were again averaged across targets to create overall scores for each dependent variable. The data were again analyzed with a 2 X 2 mixed model ANOVA. Case Type (contrast vs. target) was a within-subjects variable, and Contrast Type (strong vs. weak) was between. Table 3 shows the ANOVA statistics and Table 4 shows the descriptive statistics and planned comparisons. The planned comparison manipulation check again revealed that weak cases for parole were judged as significantly weaker than strong cases for parole on three of the four dependent variables. No 
differences for the target case evaluations were observed between the strong and weak contrast groups in terms of the parole item, perhaps because of a floor effect whereby participants were very unlikely to recommend parole at all. However, the planned comparison of the effect of contrast type on the target cases revealed that participants who evaluated strong contrast cases (i.e., prisoners with better chances for parole) gave lower evaluations to target cases. They saw them as significantly more threatening to society, less reformed, and not repentant (see Table 4).

\section{Table 3}

Study 2 Mixed-Model ANOVA Inferential Statistics

\begin{tabular}{|c|c|c|c|c|c|}
\hline & & DF & $\mathbf{F}$ & $\mathbf{p}$ & $\begin{array}{c}\eta_{\text {partial }}^{2} \\
{[90 \% \mathrm{Cl}]}\end{array}$ \\
\hline \multirow[t]{3}{*}{ THREAT } & Case Type & $1(98)$ & 8.50 & .004 & $.08[.02, .17]$ \\
\hline & Contrast Type & $1(98)$ & .91 & .342 & $.01[0, .06]$ \\
\hline & Case Type ${ }^{*}$ Contrast Type & $1(98)$ & 63.16 & $<.001$ & $.65[.27, .49]$ \\
\hline \multirow[t]{3}{*}{ NOT REFORMED } & Case Type & $1(98)$ & 7.08 & .009 & $.07[.01, .16]$ \\
\hline & Contrast Type & $1(98)$ & .39 & .533 & $0[0, .05]$ \\
\hline & Case Type * Contrast Type & $1(98)$ & 55.20 & $<.001$ & $.36[.24, .46]$ \\
\hline \multirow[t]{3}{*}{ NOT REPENTANT } & Case Type & $1(98)$ & 6.17 & .015 & $.06[.01, .15]$ \\
\hline & Contrast Type & $1(98)$ & .73 & .396 & $.01[0, .06]$ \\
\hline & Case Type * Contrast Type & $1(98)$ & 36.62 & $<.001$ & $.27[.15, .38]$ \\
\hline \multirow[t]{3}{*}{ GOOD CASE } & Case Type & $1(98)$ & 1.60 & .208 & $.02[0, .08]$ \\
\hline & Contrast Type & $1(98)$ & 1.30 & .257 & $.01[0, .07]$ \\
\hline & Case Type * Contrast Type & $1(98)$ & 8.12 & .005 & $.08[.01, .17]$ \\
\hline
\end{tabular}

This pattern of results mirrors those observed in Study 1. There, target prosecutor case strength (more likely to send to trial) was viewed more favorably by those who first saw weak contrast cases than by those who instead saw strong contrast cases. In Study 2, similarly, the target cases were evaluated more favorably by those who first saw weak contrast cases than by those who saw strong contrast cases instead. Moreover, the same crossing interaction emerged in Study 2, again demonstrating that contrast cases appeared to repel the evaluations of the target 
cases away from the evaluative anchors provided by the contrast cases. By again showing that participants evaluated prisoners' identical target cases in light of the strong or weak contrast cases with which they were embedded, this pattern of results continues to suggest that contrast effects may be one extralegal factor involved in shaping individual-level social judgments made in legal context.

\section{Table 4}

Study 2 Planned Comparison Descriptive Statistics

\begin{tabular}{|c|c|c|c|c|c|c|c|}
\hline & & & $\mathbf{n}$ & $M$ & SD & $\begin{array}{c}\text { Mean Difference } \\
{[95 \% \mathrm{Cl}]}\end{array}$ & $\begin{array}{c}\text { Cohen's D } \\
{[95 \% \mathrm{Cl}]}\end{array}$ \\
\hline \multirow[t]{4}{*}{ THREAT } & Target & Weak & 50 & 3.97 & .85 & .59 & .83 \\
\hline & & Strong & 50 & 4.56 & .53 & {$[.31, .87]$} & {$[.42,1.23]$} \\
\hline & Contrast & Weak & 50 & 4.27 & .77 & -.34 & -.48 \\
\hline & & Strong & 50 & 3.93 & .64 & {$[-.62,-.06]$} & {$[-.88,-.08]$} \\
\hline \multirow[t]{4}{*}{ NOT REFORMED } & Target & Weak & 50 & 3.93 & .94 & .62 & .81 \\
\hline & & Strong & 50 & 4.55 & .57 & {$[.32, .93]$} & {$[.40,1.22]$} \\
\hline & Contrast & Weak & 50 & 4.27 & .73 & -.45 & -.57 \\
\hline & & Strong & 50 & 3.82 & .84 & {$[-.77,-.14]$} & {$[-.97,-.17]$} \\
\hline \multirow[t]{4}{*}{ NOT REPENTANT } & Target & Weak & 50 & 3.91 & .90 & .44 & .54 \\
\hline & & Strong & 50 & 4.35 & .71 & {$[.12, .76]$} & {$[.14, .94]$} \\
\hline & Contrast & Weak & 50 & 4.10 & .84 & -.19 & -.27 \\
\hline & & Strong & 50 & 3.90 & .60 & {$[-.48, .10]$} & {$[-.66, .13]$} \\
\hline \multirow[t]{4}{*}{ DENY PAROLE } & Target & Weak & 50 & 4.05 & .90 & .07 & .08 \\
\hline & & Strong & 50 & 4.12 & .91 & {$[-.29, .43]$} & {$[-.31, .47]$} \\
\hline & Contrast & Weak & 50 & 4.39 & .75 & -.40 & -.53 \\
\hline & & Strong & 50 & 3.99 & .80 & {$[-.71,-.10]$} & {$[-.92,-.13]$} \\
\hline
\end{tabular}

\section{General Discussion}

A growing body of evidence has mounted to demonstrate that a variety of extralegal factors affect legal decision making. Often they are personal attributes, such as defendant race, gender, age, or attractiveness (Devine et al., 2001). Several decades of research in cognitive psychology has demonstrated myriad heuristics and biases that allow for quick and efficient 
decision making but that also have serious shortcomings for maximally effective reasoning (Kahneman, 2011), and recent research has also begun to explore the ways in which evaluations might be influenced by the cognitive limitations of the decision makers themselves (e.g., Leibovitch, 2016a; Leibovitch, 2016b). The present research explored how one such factor, contrast effects, might influence grand jury decision making (Study 1) and prisoner rehabilitation evaluations (Study 2).

Across two studies, we demonstrated persistent contrast effects. In Study 1, people who imagined themselves on hypothetical grand juries appeared to anchor their standards for evidentiary evaluations using recent cases they also evaluated. More specifically, target cases were evaluated to have stronger evidence and were more likely to be sent to trial if they were evaluated while embedded with weak cases. Study 2 was a conceptual replication of this effect. There, people who imagined themselves on hypothetical parole boards tended to anchor their evaluations of prisoner rehabilitation using previous cases they had evaluated as well. More specifically, compared to those who viewed strong cases for parole (i.e., better rehabilitation), those who viewed weak cases gave more positive evaluations of the target cases. Taken together, the results of these two studies suggest that contrast effects may be one extralegal factor involved in shaping individual-level social judgments made in legal contexts.

\section{Limitations and Future Directions}

Unfortunately, ecologically representative research of this nature is notoriously difficult and costly, and like many past studies we decided to use hypothetical scenarios as a first step to determine whether evidence could first be found for a basic effect. That basic effect, however, should be weighed against the fact that grand jury and parole board decisions typically involve a myriad of group process factors that were not at play in the current study. For example, 
participants in our studies had limited information about the actual details of each case (e.g., they relied largely on simply the number of pieces of evidence), and the construct validity of this proxy measure of case strength was not likely maximized. Participants may have, for instance, assumed that the limited details were the result of a lack of diligence from law enforcement agencies, prosecutors, or other legal personnel. Fortunately, these factors were constant across target cases, and the consistent pattern of results suggest effects powerful enough to overcome construct-related problems. Undoubtedly, though, members of actual grand juries and parole boards can be influenced not just by contrast effects, but also by conversations, social influence attempts, reflection after feedback, situational factors, and a variety of other things. The complexity and nuance added by a complete social environment should not be ignored, and future research on this topic should include more realistic directions, in-person simulations, or actual grand jury or parole board members. Ideally, studies would even include deliberative simulations situated in realistic environments.

Second, because the present research used a very simple design testing only the effects of contrast, it is unclear how much variance in jury or parole decision making can actually be explained by contrast effects relative to other extralegal factors. It is possible, for instance, that an actual grand jury would only be minimally affected by such effects given a richer in-person context of the courtroom, prosecutor, full access to the available evidence, etc. These factors likely play an important role in the decision making process; further research may wish to explore the relationship between contrast effects and other extralegal factors that have been the subject of previous research inquiries. It would be interesting, for example, to examine whether contrast effects interact with defendant characteristics such as gender, race, age, and attractiveness to impact favorability toward different types of people who have been accused of 
similar crimes. Finally, it is still unclear how powerful contrast effects are in relation to judicial factors like strength of evidence, and further study is necessary to determine the factors increase the likelihood of reliance on heuristic processing in legal contexts.

\section{Application}

Contrast effects have been previously noted in a wide variety of applied domains, and the present research suggests that they have value in legal context as well. For prosecutors, particularly those involved with grand juries, the results indicate the importance of the order in which they present their cases. In situations where they cannot control the order, steps may need to be taken to minimize the impact of particularly strong or weak contrast cases presented directly before or that may remain salient in jurors' minds. Prosecutors may also wish to use the effect to their advantage in similar ways, and it will be important for them to be aware of the potential that extralegal contrast could unduly influence juries unfairly. Conversely, individuals involved in criminal defense or parole application should likely do everything in their power to disassociate themselves from cases or people who would elicit contrast in the wrong direction, and similarly seek out instances of positive contrast with which to align themselves.

Members of the general public who are called to serve on grand juries should also likely be aware of contrast's extralegal influence. They have a responsibility to weigh the merits of the cases they evaluate as objectively as possible, and they often do this very well. However, in cases where the evidence is ambiguous, or it is unclear whether the strength of evidence in a case meets standards for trial, it is essential that they be made aware of that contrast effects could be sources of extralegal influence. Similarly, those who serve on parole boards take seriously their responsibility to objectively evaluate whether prisoners are rehabilitated. As a result, it is important for them to be aware of possible contrast effects as well. In general, raising awareness 
for both grand jury and parole board members would not be complex or costly. Simply providing them with information about the phenomenon may be enough to prevent its effects from taking root. However, awareness alone may not be an effective intervention (see e.g., Fischhoff, 1977), and legal professionals involved with grand juries or parole boards may wish to seek additional amelioration methods. For example, it could be useful to provide grand jury and parole board members with a standardized contrast case before each target case they consider, effectively neutralizing prior experiences and allowing for more unbiased evaluations. That being said, the effectiveness of these potential intervention, informational or otherwise, should likely be tested in either a basic or applied setting before they are put into widespread practice.

\section{Conclusion}

Ultimately, the limited capacity of human cognitive architecture has been heavily documented across a wide variety of domains, and the extralegal contrast effects shown here seem to be another example of the wide scope of heuristic processing. Although these thinking errors are commonplace, research and practical evidence in those other domains has shown their effects can be minimized or even avoided altogether under the right circumstances. In order for objectivity to be most effectively achieved across the justice system, then, it may be important to devote further study of contrast effects in a judicial context to more fully understand and limit their influence. 


\section{References}

Biernat, M. (2012). Standards and expectancies: Contrast and assimilation in judgments of self and others. Psychology Press.

Bjerregaard, B. E., Smith, M. D., Cochran, J. K., \& Fogel, S. J. (2017). A further examination of the liberation hypothesis in capital murder trials. Crime \& Delinquency, 63(8), 10171038.

Bless, H., \& Schwarz, N. (2010). Mental Construal and the Emergence of Assimilation and Contrast Effects: The Inclusion/Exclusion Model. Advances in Experimental Social Psychology, 42, 319-373

Bornstein, B. H., \& Greene, E. (2011). Jury decision making: Implications for and from psychology. Current Directions in Psychological Science, 20(1), 63-67.

Caplan, J. M. (2007). What factors affect parole-A review of empirical research. Fed. Probation, 71, 16.

Cialdini, R. B. (2009). Influence: Science and practice (Vol. 4). Boston, MA: Pearson education.

Danziger, S., Levav, J., \& Avnaim-Pesso, L. (2011). Extraneous factors in judicial decisions. Proceedings of the National Academy of Sciences, 108(17), 6889-6892.

Devine, D. J., Buddenbaum, J., Houp, S., Studebaker, N., \& Stolle, D. P. (2009). Strength of evidence, extraevidentiary influence, and the liberation hypothesis: Data from the field. Law and Human Behavior, 33(2), 136-148.

Devine, D. J., Clayton, L. D., Dunford, B. B., Seying, R., \& Pryce, J. (2001). Jury decision making: 45 years of empirical research on deliberating groups. Psychology, public policy, and law, 7(3), 622. 
Dion, K., Berscheid, E., \& Walster, E. (1972). What is beautiful is good. Journal of Personality and Social Psychology, 24(3), 285.

Eagly, A. H., Ashmore, R. D., Makhijani, M. G., \& Longo, L. C. (1991). What is beautiful is good, but...: A meta-analytic review of research on the physical attractiveness stereotype. Psychological Bulletin, 110(1), 109.

Fischhoff, B. (1977). Perceived informativeness of facts. Journal of Experimental Psychology: Human Perception and Performance, 3(2), 349.

Galesic, M., Goode, A. W., Wallsten, T. S., \& Norman, K. L. (2018). Using Tversky’s contrast model to investigate how features of similarity affect judgments of likelihood. Judgment and Decision Making, 13(2), 163.

Gunnell, J. J., \& Ceci, S. J. (2010). When emotionality trumps reason: A study of individual processing style and juror bias. Behavioral sciences \& the law, 28(6), 850-877.

Hester, R., \& Hartman, T. K. (2017). Conditional race disparities in criminal sentencing: a test of the liberation hypothesis from a non-guidelines state. Journal of Quantitative Criminology, 33(1), 77-100.

Johnson, T. J., Ellison, A. M., Dalembert, G., Fowler, J., Dhingra, M., Shaw, K., \& Ibrahim, S. (2017). Implicit Bias in Pediatric Academic Medicine. Journal of the National Medical Association, 109(3), 156-163.

Jones, E. E., Palmer Jr, P. G., \& Bandy, A. D. (2015). The effect of inconsistency on evaluations of a second eyewitness: It depends on who testifies first. Psychiatry, Psychology and Law, 22(6), 814-829.

Kahneman, D. (2011). Thinking, fast and slow. Macmillan. 
Kahneman, D., \& Tversky, A. (1979). Prospect theory: An analysis of decisions under risk. Econometrica, 47, 278.

Kalven, H., Zeisel, H., Callahan, T., \& Ennis, P. (1966). The american jury (p. 498). Boston: Little, Brown.

Kenrick, D. T., \& Gutierres, S. E. (1980). Contrast effects and judgments of physical attractiveness: When beauty becomes a social problem. Journal of Personality and Social Psychology, 38(1), 131.

Kramer, G. P., Kerr, N. L., \& Carroll, J. S. (1990). Pretrial publicity, judicial remedies, and jury bias. Law and Human Behavior, 14(5), 409.

Leibovitch, A. (2016a). Punishing on a Curve. Nw. UL Rev., 111, 1205.

Leibovitch, A. (2016b). Relative judgments. The Journal of Legal Studies, 45(2), 281-330.

Ley, B. L., Jankowski, N., \& Brewer, P. R. (2012). Investigating CSI: Portrayals of DNA testing on a forensic crime show and their potential effects. Public Understanding of Science, 21(1), 51-67.

Locke, J. (1690). An Essay Concerning Humane Understanding. (1st ed). London: Thomas Bassett

London, K., \& Nunez, N. (2000). The effect of jury deliberations on jurors' propensity to disregard inadmissible evidence. Journal of Applied Psychology, 85(6), 932.

Lorenzo, G. L., Biesanz, J. C., \& Human, L. J. (2010). What is beautiful is good and more accurately understood: Physical attractiveness and accuracy in first impressions of personality. Psychological Science, 21(12), 1777-1782. 
McNamara, T. K., Pitt-Catsouphes, M., Sarkisian, N., Besen, E., \& Kidahashi, M. (2016). Age bias in the workplace: cultural stereotypes and in-group favoritism. The International Journal of Aging and Human Development, 83(2), 156-183.

Moskowitz, G. B. (2005). Social Cognition: Understanding Self and Others. Guilford Press.

Moskowitz, G. B., \& Roman, R. J. (1992). Spontaneous trait inferences as self-generated primes: Implications for conscious social judgment. Journal of Personality and Social Psychology, 62, 728-738.

Newman, L. S., \& Uleman, J. S. (1990). Assimilation and contrast effects in spontaneous trait inference. Personality and Social Psychology Bulletin, 16, 224-240.

Nisbett, R. E., \& Ross, L. (1980). Human inference: Strategies and shortcomings of social judgment.

Nugent, D. C. (1994). Judicial Bias. Clev. St. L. Rev., 42, 1.

Parker, S., Bascom, J., Rabinovitz, B., \& Zellner, D. (2008). Positive and negative hedonic contrast with musical stimuli. Psychology of aesthetics, creativity, and the arts, 2(3), 171.

Patry, M. W. (2008). Attractive but guilty: Deliberation and the physical attractiveness bias. Psychological Reports, 102(3), 727-733.

Pepitone, A., \& DiNubile, M. (1976). Contrast effects in judgments of crime severity and the punishment of criminal violators. Journal of Personality and Social Psychology, 33(4), 448.

Plous, S. (1993). The Psychology of Judgment and Decision Making. McGraw-Hill.

Ruva, C. L., \& Guenther, C. C. (2017). Keep your bias to yourself: How deliberating with differently biased others affects mock-jurors' guilt decisions, perceptions of the defendant, memories, and evidence interpretation. Law and Human Behavior, 41(5), 478. 
Sherif, M., \& Hovland, C. (1961). Social Judgment, Assimilation and Contrast Effects in Communication and Attitude Change. New Haven, CT: Yale University Press.

Spohn, C., Gruhl, J., \& Welch, S. (1987). The impact of the ethnicity and gender of defendants on the decision to reject or dismiss felony charges. Criminology, 25(1), 175-192.

Steblay, N. M., Besirevic, J., Fulero, S. M., \& Jimenez-Lorente, B. (1999). The effects of pretrial publicity on juror verdicts: A meta-analytic review. Law and Human Behavior, 23(2), 219.

Tversky, A. (1977). Features of similarity. Psychological Review, 84, 327-352.

Tversky, A., \& Kahneman, D. (1974). Judgment under uncertainty: Heuristics and biases. Science, 185(4157), 1124-1131.

Wundt, W. M. (1907). Outlines of psychology. W. Engelmann. 


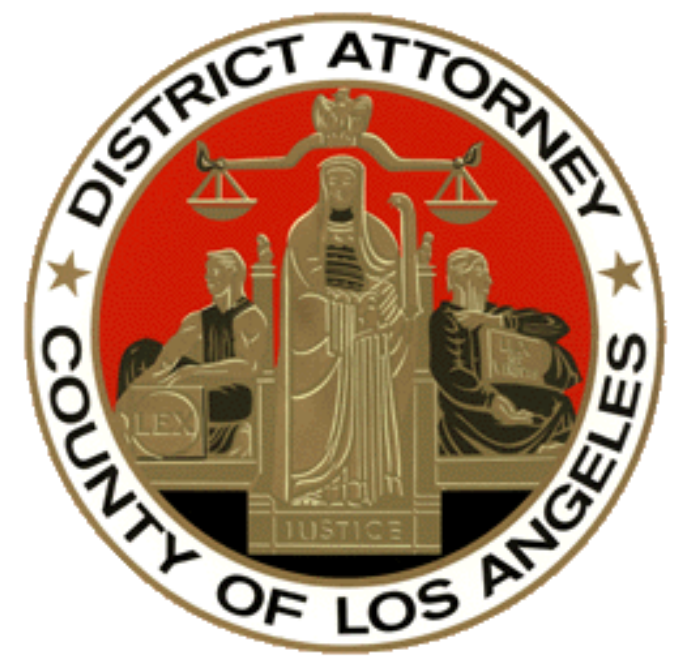

Simplified Grand Jury Information

Defendant: Michael Anderson

Crime: Assault with a deadly weapon

\section{Character}

- Friends believe he has the capacity to be dangerous

- A psychological evaluation revealed areas of concern

$\underline{\text { Known Facts }}$

- Was seen loitering near the scene of the crime earlier that day by two witnesses 
Appendix B: Study 2 Sample Target Case File

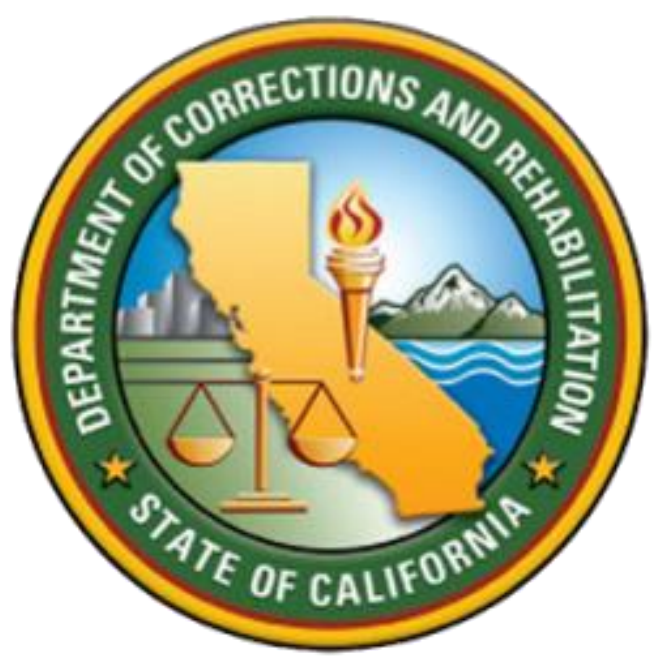

Simplified Parole Board Information

Prisoner: John Hall

Crime: Assault with a deadly weapon

$\underline{\text { Character }}$

- Prison counselors believe he has the capacity to be dangerous

- A psychological evaluation revealed areas of concern

$\underline{\text { Infractions }}$

- Was found vandalizing prison grounds 